Para enlazar con este artículo / To link to this article:

http://dx.doi.org/10.6035/MonTI.2019.ne5.3

Para citar este artículo / To cite this article:

Hernández Guerrero, María José. (2019) "La traducción en las nuevas formas de periodismo." En: Montero Küpper, Silvia; Montse Vázquez Gestal \& Iván Puentes Rivera (eds.) 2019. Comunicación, Traducción e Interpretación / Communication, Translation and Interpreting. MonTI Special Issue 5, pp. 72-93.

\title{
LA TRADUCCIÓN EN LAS NUEVAS FORMAS DE PERIODISMO
}

\author{
TRANSLATION IN NEW FORMS OF JOURNALISM
}

\author{
MARÍA JosÉ HERNÁNDEZ GUERRERO \\ mjhernandez@uma.es \\ Universidad de Málaga
}

\section{Resumen}

La traducción permite a las empresas de comunicación generar y distribuir material periodístico más allá de fronteras nacionales y lingüísticas. Traducir para producir nuevos contenidos es algo que se hace constantemente y se considera como una parte más de la labor periodística. Además, las empresas periodísticas se sirven de la traducción para crecer, llegar a nuevas audiencias y alcanzar un mayor impacto social. En este trabajo se analiza el papel de la traducción en las nuevas formas de periodismo surgidas del cambio radical que se ha producido en el entorno digital. El uso de la traducción en este nuevo contexto periodístico se ha multiplicado y es necesario un acercamiento a esta nueva realidad. Nuestro objetivo es exponer la actividad traductora que se está llevando a cabo en el nuevo periodismo mediante la descripción y el análisis de diferentes casos: medios digitales, aplicaciones móviles, redes sociales y plataformas multimedia.

Palabras clave: Traducción periodística; Medios digitales; Redes sociales; Plataformas multimedia; Aplicaciones móviles 


\begin{abstract}
Translation allows news organizations to generate and distribute journalistic material beyond national and linguistic boundaries. Translating to produce new content is something that is done constantly and is considered as an integrated part of journalistic work. In addition, communication companies use translation to grow, reach new audiences and achieve a greater social impact. This article analyzes the role of translation in new forms of journalism emerged from the radical change that has taken place in the digital environment. The use of translation in this new journalistic context has multiplied and an approach to this new reality is necessary. Our objective is to expose the translation activity occurring at the new journalism by describing and analyzing different cases: digital media, mobile applications, social media and multimedia platforms.
\end{abstract}

Keywords: News translation; Digital media; Social media; Multimedia platforms; Mobile applications

\title{
1. Introducción
}

En la actualidad, asistimos a un continuo trasvase de los flujos informativos en un complejo proceso de comunicación transcultural solo posible gracias a la traducción. La globalización no ha hecho más que acentuar esta tendencia, agilizada por el avance tecnológico digital de las últimas décadas, que afecta de manera general a todo el sector periodístico, independientemente del soporte técnico que se utilice para difundir la información (periodismo impreso, audiovisual y digital o multimedia).

La traducción permite a las empresas de comunicación elaborar y distribuir material periodístico más allá de fronteras nacionales y lingüísticas. La actividad traductora que se desarrolla en estas organizaciones, denominada traducción periodística, se viene considerando como una subárea de los Estudios de Traducción (Valdeón 2015). En los últimos años, varias obras se han ocupado del papel que desempeña la traducción en la transmisión de los mensajes periodísticos, cómo se utiliza y con qué objetivos (Cortés Zaborras y Hernández Guerrero 2005; Bielsa y Bassnett 2009; Hernández Guerrero 2009; Valdeón 2010 y 2012; Davier 2017; Scammell 2018). Sorprende, sin embargo, la ausencia de reflexiones por parte del ámbito periodístico que, si bien incide en la labor de mediación de la prensa entre los acontecimientos 
y el público, descuida el análisis de la doble mediación que se produce al traducir la información, con muy escasas excepciones (Wilke \& Rosenberger 1994; Hernando 1999; Gallardo Camacho 2005; Palmer 2009; Baumann, Gillespie \& Sreberny 201 la y 2011b; Valdeón 2018).

El avance digital de las últimas décadas ha afectado de manera general a todo el sector de la comunicación, independientemente del soporte utilizado para la transmisión de la información. Los estudios de comunicación se han ocupado de las nuevas formas de periodismo surgidas de la innovación tecnológica (cf. Gillmor 2004 y 2010; López García 2010; Salaverría 2005; Allan \& Thorsen 2009; Rosenberry \& St John 2010; Lule 2012), pero lo han hecho sin reparar en el papel que desempeña la traducción. Sin embargo, la actividad traductora en estos nuevos medios se ha multiplicado y no deja de crecer.

Este trabajo presenta un primer acercamiento a esta realidad. Se ocupa de la presencia de la traducción en las nuevas formas de periodismo surgidas del cambio radical que se ha producido con el avance digital. Nuestro objetivo es describir y analizar la actividad traductora que se lleva a cabo en el nuevo periodismo centrándonos en diferentes casos. Hemos estructurado nuestro estudio de la siguiente forma: tras este primer apartado, presentamos una breve introducción a la traducción periodística y sus principales rasgos; a continuación, nos ocupamos del uso de la traducción en las nuevas formas de periodismo: ediciones digitales, medios alternativos, aplicaciones móviles para medios, redes sociales y plataformas multimedia.

\section{La traducción periodística}

La actividad traductora que llevan a cabo las empresas de comunicación se rige por las pautas propias del marco periodístico. Los medios de comunicación actúan necesariamente sobre la información que hacen llegar a sus públicos; la seleccionan, la elaboran, la ilustran, le dedican mayor o menor relevancia... Además, cada uno de ellos presenta rasgos diferenciadores que responden a unos principios editoriales, a un estilo comunicativo, a un diseño y a una identidad empresarial. Traducir para producir contenidos es algo que se hace con mucha frecuencia y no se considera como una ocupación distinta de la periodística, sino como una parte más de esta; el trabajo de los redactores consiste en elaborar nueva información y, si para ello han de servirse 
de la traducción, lo hacen de formas muy variadas que en ocasiones no coinciden con el concepto tradicional que se tiene de la traducción: su finalidad a menudo no es reproducir un determinado original, sino producir nueva información para un marco comunicativo muy concreto partiendo de material informativo en otras lenguas. En los medios se traduce con la finalidad de generar información que responda a las expectativas de la audiencia local y a los intereses (económicos, ideológicos...) del grupo de comunicación. La prioridad es informativa, y a ella se supedita la labor lingüística (Hernández Guerrero 2009: 33). El principal objetivo de la traducción periodística, por tanto, es la transmisión de la información de una manera clara para que llegue a su público de forma efectiva.

Los estudios realizados hasta la fecha sobre la utilización de la traducción por parte de las empresas periodísticas han destacado una serie de rasgos, que presentamos en los siguientes epígrafes.

\subsection{Invisibilidad y transparencia}

La actividad traductora en los medios es constante. Su presencia, sin embargo, no es visible, pues el flujo incesante de material traducido se diluye y se entremezcla, en el proceso de generación de nueva información, con el material periodístico que se produce en las redacciones, pasando a formar parte de la producción propia de los medios. A esta invisibilidad de la traducción se añade su transparencia, entendida como una manera de enfocar la mediación en la que los textos se adaptan a las normas de la cultura receptora, minimizando las diferencias lingüísticas y culturales en aras de la fluidez. Las audiencias prefieren recibir la información en su propia lengua y de la forma en que convencionalmente la han recibido.

Como señalan Bielsa \& Bassnett (2009), la invisibilidad y la transparencia de la traducción en la transmisión del flujo informativo global han creado la sensación de que la información circula inalterada entre comunidades lingüísticas y culturales diferentes, cuando la realidad es bien distinta: el doble proceso de mediación al que es sometida la altera. 


\subsection{Transedición}

Para elaborar nueva información a partir de material periodístico en otras lenguas, cada medio de comunicación sigue fórmulas de producción propias: selecciona qué se traduce, establece con qué función y lo transmite con el sello de su línea editorial; todo el proceso está supeditado a sus necesidades en materia de información (Hernández Guerrero 2009: 58).

Los profesionales que se ocupan de esta labor aúnan en el mismo proceso la labor de traducción y de edición. Es lo que se conoce como transedición -término acuñado por Stetting (1989)-. Para esta investigadora (1989: 377), la transedición cubre estas tres áreas: 1) Adaptación al estándar de eficiencia en la expresión. 2) Adaptación a la función establecida para el texto traducido en el nuevo contexto social. 3) Adaptación a las necesidades y convenciones de la cultura de llegada. La transedición implica reorganizar la información, añadir información adicional, suprimir pasajes que no se consideren relevantes para el nuevo receptor, condensar otros, introducir los elementos de titulación, etc., a partir de material en otras lenguas. Es un tipo de tarea que requiere del profesional una mayor competencia (destrezas en traducción y en periodismo) para lograr con éxito la elaboración y producción del nuevo material informativo.

\subsection{Recontextualización}

En el marco periodístico se traduce para crear nueva información que, total o parcialmente, se genera a partir de otros textos. Los profesionales que llevan a cabo esta labor no buscan reproducir un texto previo, no es esa su finalidad. No actúan como simples mediadores en el trasvase de la información, sino que adoptan un papel más activo. Son parte del proceso de gatekeeping (Valdeón 2016), es decir, actúan de filtro y seleccionan qué elementos de una información se van a difundir. Vuorinen (1995: 170) considera que, en este proceso, operaciones como la omisión, adición, substitución y reorganización son "part and parcel of the normal text operations performed in any translation, and particularly in news translation".

Estas intervenciones implican transformaciones que van más allá del mero trasvase lingüístico. Las miras de estos profesionales están puestas en la función que debe cumplir la noticia en su nuevo contexto sociocultural 
y para ello no solo la filtran, traducen y editan, también la recontextualizan para el medio de comunicación local y su audiencia. No muestran fidelidad al texto de partida, sino a las directrices para la producción de información que reciben de sus empresas. Para Verscheuren (2007), "Recontextualization of texts affects their meaning, function and reception: a translated text not only involves linguistic displacement but also contextual/cultural dislocation". En este proceso de recontextualización, el medio de comunicación impone sus criterios sobre cómo se procesará la información y cómo se presentará a la audiencia.

\subsection{Localización}

En un principio, la localización ${ }^{1}$ se confundía con un tipo de traducción especializada y se asociaba a la traducción informática, aunque los productos sometidos a este proceso pueden ser muy variados. Pym (2004: 4) considera que los textos informativos son también productos localizados: "The foreign news we read in the local press can legitimately be seen as a localization of foreign-language texts, at some point transformed by the international agencies, and transformed in ways that go beyond endemic notions of translation". Las noticias fueron el primer producto de información global en ser localizado. Profundizando en esta idea, Orengo (2005) apunta que el proceso de localización se hace a medida del nuevo perfil social, cultural y político de la audiencia local. El mercado de noticias implica su traducción a otras lenguas como requisito previo para su distribución global. El proceso de publicación de un texto de una agencia de noticias se corresponde con el paso de un producto global a una versión localizada por un medio local (2005: 175).

\section{Traducción y nuevas formas de periodismo}

En las últimas décadas hemos sido testigos del surgimiento de nuevas formas de periodismo propiciadas por el auge de las tecnologías de la comunicación

1. La Guía de introducción al sector de la localización la define así: "La localización es el proceso de adaptación y fabricación de un producto para que presente el aspecto y el funcionamiento de un artículo fabricado en un país en concreto. Así pues, la localización es la pieza de un rompecabezas comercial mundial que permite que las empresas mantengan negocios en mercados ajenos al suyo original" (Fry 2003: 3). 
y especialmente por el desarrollo de la Web 2.0: medios digitales, periodismo ciudadano, blogs, webs, redes sociales, plataformas multimedia... La tradicional relación entre los medios y sus audiencias se ha visto totalmente alterada, tanto por las oportunidades de participación que ofrecen los medios digitales como por su contextualización en un ciberentorno en el que ya no es posible entender la figura de un receptor pasivo. Han surgido, por tanto, nuevas formas de periodismo que funcionan en un marco comunicativo muy diferente al de los medios tradicionales.

Con el periodismo digital, además, las fronteras nacionales y lingüísticas se mueven y se diluyen. En este nuevo marco, las empresas periodísticas se sirven de la traducción no solo para producir nueva información, sino también para crecer, llegar a nuevas audiencias y alcanzar un mayor impacto social. Como ya se ha señalado repetidamente desde el ámbito académico (cf. Bielsa \& Bassnett 2009; Hernández Guerrero 2009; Valdeón 2015), para estudiar la complejidad de este fenómeno, se necesita un marco metodológico interdisciplinar que combine los Estudios de Traducción, las Ciencias de la Comunicación, la Teoría Social...

El uso de la traducción en este nuevo contexto se ha multiplicado, pero apenas si se le ha prestado atención. En los siguientes epígrafes proponemos un acercamiento a esta nueva realidad a través de la descripción y análisis de la actividad traductora que se lleva a cabo en el nuevo periodismo centrándonos en diferentes casos.

\subsection{Ediciones digitales multilingües}

Las nuevas tecnologías han brindado a los medios de comunicación nuevos soportes y canales para el desarrollo de sus funciones y, al mismo tiempo, han propiciado el surgimiento de nuevos medios que compiten con los tradicionales en el ciberespacio. Algunos buscan una repercusión mayor que la proporcionada por una audiencia local y recurren a ediciones digitales multilingües, que ofrecen un mayor alcance. El punto de arranque de estas iniciativas es la constatación de que "linguistic difference persists in the face of globalization, and this difference is a barrier to connection and understanding" (Zuckerman 2013: 134). Las ediciones multilingües no siguen un patrón uniforme. Cada medio dispone de su propio modelo de organización, su línea informativa y 
editorial, su método de recogida y búsqueda de información, etc... Por esta razón, la casuística es muy amplia. Hay medios tradicionales que migraron a la red, donde volcaron sus ediciones en papel, para posteriormente pasar a potenciar sus ediciones electrónicas. Un ejemplo cercano es el caso del diario El País y la evolución de su edición digital, que data de 1996. A su conocida edición en inglés, sumó a finales de noviembre de 2013, pocos meses después del lanzamiento de la edición América, su edición brasileña donde, como señalan los análisis de Paula Batista (2016: 205), "la traducción asume un papel crucial, pero también invisible a la vez". En 2014 lanzó la web en catalán -aunque El País contaba desde 1982 con información en catalán en su edición impresa- que traduce las noticias más importantes de la web de El País y, además, genera temas propios y exclusivos para elpais.cat, con la idea de que sea un medio "global y local".

Otro caso muy distinto es del Huffpost (anteriormente The Huffington Post), un proyecto periodístico nacido en y para Internet. Lanzado por Arianna Huffington en Estados Unidos en 2005, fue adquirido por American Online en 2011 y comenzó una expansión internacional que se ha traducido en el lanzamiento de ediciones en francés, español, italiano, alemán, japonés, árabe, portugués, etc. Su proceso de expansión global se sustenta en alianzas locales con medios tradicionales afines a su línea editorial. Se trata generalmente de influyentes grupos mediáticos que permiten anclar a la empresa estadounidense en las nuevas sociedades a las que quiere llegar y posibilita que sus distintas ediciones se redacten directamente en la lengua de la comunidad de llegada, sin necesidad de recurrir a la traducción. Con sus blogs de audiencia -uno de los pilares básicos sobre los que se sustenta-, este cibermedio ofrece espacios a los blogueros para que generen opinión escrita y utiliza la traducción para que algunas de esas opiniones alcancen mayor resonancia, reproduciéndolas en sus distintas ediciones internacionales (Hernández Guerrero 2015).

Estos dos casos son ejemplos de empresas periodísticas pertenecientes a grandes grupos de comunicación, de alcance global. Pero la red también es el espacio de los llamados medios independientes y medios alternativos. Los primeros son nuevas fórmulas periodísticas que no se financian con publicidad ni con el capital de grandes corporaciones; mantienen su independencia con las aportaciones económicas que realizan sus suscriptores o algunas 
fundaciones. Un ejemplo es Mediapart, una plataforma periodística francesa creada en 2008, que se ha convertido en un referente a nivel internacional como fórmula rentable de hacer periodismo independiente y de calidad utilizando las herramientas que ha aportado la revolución digital. Es un diario de pago que entró en beneficios en su tercer año funcionamiento. Mediapart ofrece esencialmente periodismo de investigación en una estructura dual que comprende los artículos redactados por su propio equipo (le Journal) y los de sus suscriptores o socios (le Club). Mediapart utiliza la traducción para dar un mayor alcance a su proyecto. En 2010 creó una edición en inglés y en 2013 otra en español -Mediapart English y Mediapart Español-, donde la traducción de artículos de la matriz francesa se combina con los contenidos producidos en esas lenguas por Propublica e Infolibre, dos medios independientes de investigación que comparten propósitos similares, con los que se han tejido redes de intercambio que buscan expandir e interconectar sus propuestas (Hernández Guerrero 2017).

No podemos dejar al margen la importancia de los factores económicos en todo este proceso:

Las empresas periodísticas persiguen su rentabilidad en un mercado cambiante y muy competitivo. Generar información a partir de un material ya elaborado reduce los costes empresariales, al igual que compartir contenidos con otras publicaciones estableciendo acuerdos de asociación. Esta política empresarial implica traducir, pues la traducción resulta económicamente más ventajosa que la producción de nuevos contenidos (Hernández Guerrero 2009: 80).

Los segundos, los medios alternativos, han surgido de la pérdida de confianza de los ciudadanos en los medios de comunicación dominantes. Su finalidad es la libertad de prensa. Son mucho menos visibles e infinitamente menos poderosos, pero recurren a la traducción como arma que multiplica el eco de sus mensajes y les proporciona mayor proyección en la red. En palabras de Talens (2010a: 124-125), "la columna vertebral de los medios alternativos es la traducción. Sin ella tendrían muy poca pegada". Muy pocos trabajos se han ocupado de la actividad traductora en estas publicaciones electrónicas (cf. Juris 2004; Pérez González 2010; Salzberg 2008; Talens 2010a y 2010b; Baker 2012). Al igual que los medios tradicionales, estos medios disponen de su propio modelo de organización, como se aprecia en los siguientes casos. 
Independent Media Center, más conocido como Indymedia, es una de estas iniciativas activistas. Surgida en 1999 en Seattle, se ha extendido a Europa, América del Sur, África y Asia. Indymedia está organizada de forma descentralizada y horizontal. Cada sitio web local es autónomo, pero está conectado a una red más amplia, lo que facilita el intercambio de ideas, recursos e información. Como señala Juris (2004: 166-169), estos activistas utilizan un programa de publicación abierta, que se adapta en las distintas sedes a las necesidades locales (en Barcelona, por ejemplo, funciona de forma trilingüe en castellano, catalán e inglés). Para la comunicación transnacional y la coordinación, utilizan el correo electrónico, las listas de distribución, el software de traducción y los foros.

Otro caso, muy distinto, lo tenemos en Rebelión, iniciativa de un colectivo de periodistas españoles sin ánimo de lucro, en funcionamiento desde 1996. Surge para impulsar otro modelo de comunicación: noticias que no son consideradas importantes por los medios de comunicación dominantes. Publica traducciones de diversos autores y difunde artículos de otros medios. Rebelión cuenta con un equipo de traducción al español desde otros idiomas formado por aproximadamente unas quince personas ${ }^{2}$.

El caso más estudiado, hasta la fecha, es el de Tlaxcala, la red internacional de traductores por la diversidad lingüística (Talens 2010a y 2010b; Baker 2012). La peculiaridad de este medio, nacido en 2005 y que en la actualidad difunde información en quince lenguas, es que fue creado por traductores, aunque en sus filas colaboren voluntariamente periodistas, escritores, académicos, etc. Esta iniciativa mediática traduce artículos contrarios al pensamiento único que aparecen en los medios alternativos ${ }^{3}$, ayudando a difundir a autores desconocidos o limitados a sus ámbitos lingüísticos. Sin esas traducciones, las denuncias locales seguirían siendo locales.

2. La información sobre el surgimiento de este medio y sus componentes puede consultarse en el siguiente enlace: https://www.rebelion.org/nosotros.php.

3. Su ideario se puede consultar en el "Manifiesto de Tlaxcala": http://www.tlaxcala-int. org/manifeste.asp 


\subsection{Aplicaciones móviles para medios}

La revolución digital ha conseguido transformar la forma de hacer y consumir información. El número de lectores que acceden a los medios de comunicación mediante dispositivos móviles no deja de crecer. Las empresas periodísticas, con el objetivo de incrementar el número de usuarios, aumentar su audiencia y la difusión de su marca, han desarrollado aplicaciones para estos dispositivos, de tal modo que en la actualidad prácticamente todos los medios tienen su propia app.

En un principio, cuando comenzaron a popularizarse los teléfonos inteligentes, los medios lanzaron aplicaciones que eran poco más que un reflejo de su web. Con el tiempo, han ido evolucionando y ahora muchas de ellas abren un abanico de nuevas opciones a sus usuarios: alertas con noticias de última hora; nuevas tecnologías como la realidad virtual; aplicaciones especiales para eventos; elección del contenido para descargar y poder acceder a él en lectura sin conexión; versión oscura para mayor legibilidad en entornos oscuros; portada personalizada con los temas de interés del lector organizados en su orden de preferencia...

Las empresas informativas se han servido, pues, de los avances tecnológicos y han adaptado sus productos a las nuevas formas de consumir información y también de ofrecerla. Algunas, además, se están sirviendo de estos soportes en su proceso de internacionalización mediante la traducción de sus contenidos.

Es el caso de BeSoccer, un sitio de información especializada sobre fútbol. Se trata de una empresa española que comenzó a funcionar en 2009. Resultados de Fútbol es uno de sus productos más exitosos. Como explica Torregrosa (2017), "es una aplicación que recoge la totalidad de partidos y datos del planeta fútbol. Con esta 'app' podemos conocer desde los resultados en directo de los encuentros de la Tercera División Rusa hasta los de la Segunda de Venezuela, pasando por las grandes ligas y toda la cantera nacional". Además, "BeSoccer cuenta con un departamento editorial que informa al minuto de todas las novedades que ocurren en el fútbol mundial. Crónicas, noticias en directo, fichajes y toda la actualidad están recogidas en su aplicación y su web". 
El éxito de esta iniciativa derivó en la creación de departamentos editoriales en francés, inglés y portugués, que comenzaron con la traducción de contenidos. Posteriormente, pasaron a elaborar noticias propias y crear contenido nuevo en esas lenguas. García Alarcón (2017: 107), basándose en su experiencia como traductora en la edición francesa, enumera las diferentes funciones que los traductores realizan en esta empresa:

- Traducir noticias: se suele tomar como texto original las noticias creadas en español. En la mayoría de los casos, las noticias suelen ser traducidas total o parcialmente y se seleccionan aquellas que pueden resultar de interés para el público francófono, como las relativas a equipos importantes de las principales ligas europeas.

- Traducir contenido audiovisual: se traducen gráficos, imágenes interactivas o vídeos que más tarde deben ser maquetados y revisados de nuevo.

- Redactar noticias relacionadas con las ligas francesas o africanas. En numerosas ocasiones estas noticias no existen en la versión en español, y los traductores deben entonces ejercer como periodistas esencialmente y buscar información para crear una noticia desde cero.

- Editar y revisar las noticias de agencias. A la redacción llegan noticias provenientes de la agencia francesa AFP, pero estas suelen venir con algunos errores o marcas ortotipográficas no aceptadas por esta empresa. Por ello, todas estas noticias deben pasar por el filtro lingüístico y ortotipográfico del traductor. Desde el punto de vista de su contenido, este revisor deberá también juzgar el interés de este contenido.

- Editar y revisar noticias de colaboradores. Como hemos dicho anteriormente en este trabajo, una de las características fundamentales de los nuevos medios de comunicación es que estos se nutren de otros usuarios. En este caso, la empresa trabaja con algunos colaboradores externos, simples aficionados al fútbol, a los que se le brinda la oportunidad de escribir alguna noticia sobre lo que acontece en su país. Este artículo debe ser revisado y editado por el traductor en plantilla.

- Control de calidad y revisión de la página web y aplicación móvil.

- Mantener las redes sociales actualizadas. Como cualquier medio de comunicación digital, este tiene también cuentas oficiales en las principales redes sociales.

Además de estas actividades, al traductor-periodista se le exigen también unos conocimientos para llevar a cabo esta labor traductora:

- Conocimientos bilingües de las dos lenguas de trabajo (en nuestro caso, francés y español). 
- Conocimientos de fútbol. No solo es importante a la hora de traducir conocer la terminología de este sublenguaje, sino que también es relevante cuando debemos clasificar esta información por orden de importancia.

- Conocimientos informáticos y de redes sociales.

Con la llegada de los teléfonos inteligentes, se ha creado un espacio de necesidades que los grupos de comunicación deben cubrir. Muchas empresas informativas se han hecho con un hueco significativo en el mercado de las apps y logran su éxito gracias al conocimiento de sus usuarios, que les permite gestionar las necesidades cercanas de sus audiencias y sus diferencias dentro del mercado. Además de redactores en otros idiomas, estos medios se nutren de otros perfiles profesionales: creadores y gestores de contenidos, desarrolladores web y de aplicaciones, etc. A las destrezas en periodismo y traducción, hay que sumar las nuevas tecnologías.

\subsection{Las redes sociales}

No decimos nada nuevo al afirmar que las redes sociales han transformado las salas de redacción agilizando la recopilación de noticias y aumentando el número de fuentes y de material disponible. Estas plataformas se han introducido en el campo de la información con formatos nuevos y con millones de lectores, compitiendo con otros medios digitales. Además, la creación de sitios de noticias por parte de estas redes las posiciona como canales de distribución y difusión periodísticas.

El caso de FB Newswire, la página de Facebook que funciona como agencia de noticias, resulta bastante ilustrativo. Comenzó su andadura en abril de 2014, con la idea de servir de herramienta a periodistas y redacciones para encontrar, compartir e incrustar noticias confirmadas desde Facebook. Mediante este servicio se ponen en circulación informaciones creadas tanto por usuarios individuales como por organizaciones, a través de sus gabinetes de prensa y comunicación. FB Newswire funciona como un intermediario informativo (Casero-Ripollés 2015: 174): "Su actividad se sitúa a medio camino entre la edición, la agregación y la difusión, pero como elemento distintivo destaca que no produce contenidos propios, sino que empaqueta y distribuye los ajenos". 
Otro tanto sucede con Twitter, que se ha convertido en un auténtico proveedor de noticias, de tal modo que ya resulta impensable que los medios de comunicación ignoren o descarten estas redes. Dependen de ellas para proporcionar información en tiempo real, reacciones y opiniones mientras el hecho se está produciendo. Por otro lado, el rol de los medios ha cambiado significativamente con la irrupción de este periodismo ciudadano: una persona que esté en el lugar de los hechos puede informar de lo que está sucediendo de forma instantánea. Señala Plaza Écija (2013) que, en el nuevo periodismo, Twitter se está convirtiendo en uno de los medios más importantes:

Aunque Twitter no sea considerado un medio de comunicación como tal, en lugares donde los medios tradicionales no informan correctamente se convierte a veces en la fuente de información que más importa. Twitter ha demostrado su utilidad como fuente de noticias en tiempo real en numerosas ocasiones, pero en la mayoría de los casos es un medio más que compite por la audiencia y la atención del público.

De hecho, un estudio realizado por un equipo del Korea Advanced Institute of Science and Technology (Kwak et al. 2010) demostró que el uso que se está haciendo de Twitter se ajusta más a la definición de medio de comunicación que a lo que conocemos como redes sociales. Sus usuarios se registran para recibir información y suelen hablar de temas de actualidad, algo que se ajusta a la definición amplia de noticia. El impacto de esta plataforma es especialmente visible en las noticias de última hora. Entre los ejemplos de acontecimientos notables que exponen los investigadores se halla el accidente del avión de la compañía Airways en el río Hudson, en enero de 2009. Las primeras informaciones del accidente fueron difundidas en Twitter por testigos presenciales.

Twitter es también una fuente atractiva para los periodistas, que siguen las discusiones sobre temas de actualidad y rastrean los tuits en busca de citas interesantes para sus artículos. En ocasiones, son los propios tuits los que se convierten en noticia. Ya nos hemos acostumbrado, por ejemplo, a encontrar los omnipresentes tuits de Donald Trump reproducidos en todos los medios, a veces como cita entrecomillada, otras veces en forma de captura de pantalla. Decía Jordi Soler en uno de sus artículos que “... cuando quiere hacer temblar al planeta Donald Trump no convoca a una rueda prensa: lanza un tuit" (Soler 2017). Este caso resulta de lo más elocuente para el tema que nos 
ocupa, ya que Trump los escribe en inglés. Cuando sus tuits se convierten en noticia para los medios internacionales, suelen publicarse como un original con su traducción (véase Figura 1), sacando a la traducción periodística de su invisibilidad. La proliferación generalizada de estos usos, que no han sido aún estudiados, no hace más que poner en evidencia la presencia de la traducción en los medios.

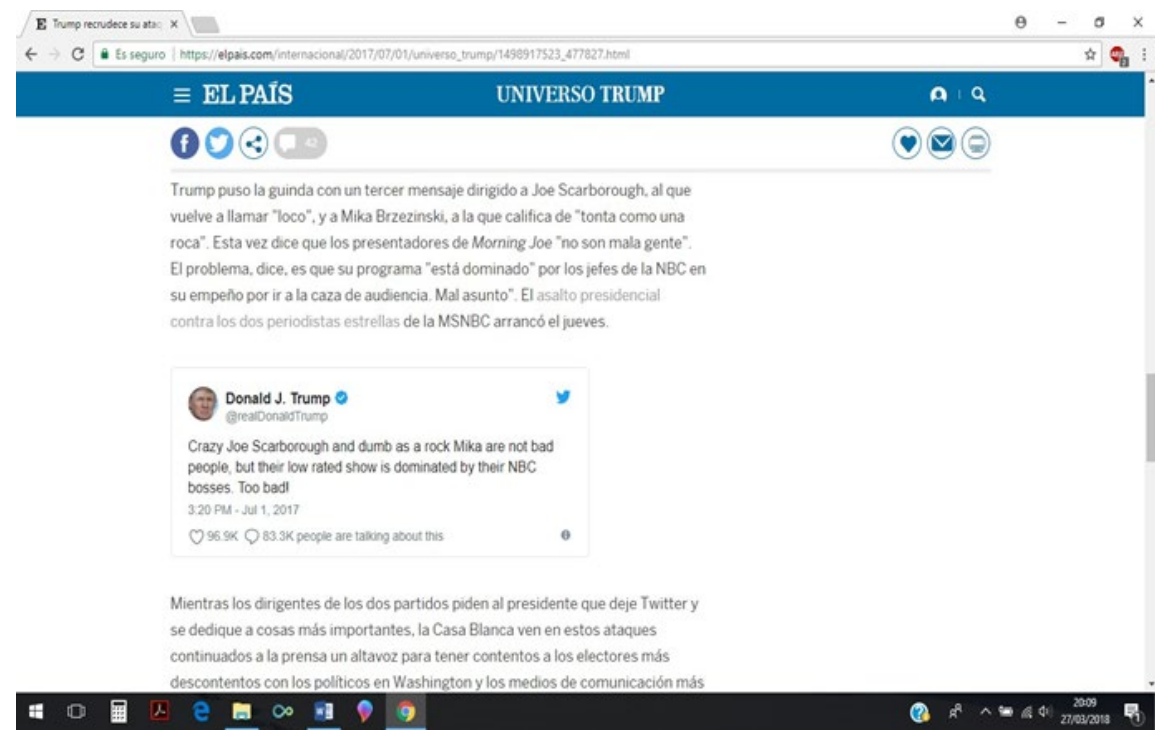

Figura 1: https://elpais.com/internacional/2017/07/01/universo_ trump/1498917523_477827.html

\subsection{Plataformas multimedia}

Cada vez son más las empresas periodísticas que se están transformado en plataformas multimedia, ya que crear y ofrecer contenidos desde estos portales les proporciona una mayor repercusión. Las piezas periodísticas se conciben, ahora, para que puedan ser contadas en radio, en televisión y en la web. Esto implica el desarrollo de nuevos lenguajes informativos que permitan integrar adecuadamente esos tres códigos que son el texto, la imagen y el sonido, y presentarlo en un producto informativo único. 
Si lo que se pretende es un alcance global, además de multimedia, estas plataformas han de ser multilingües y, por tanto, utilizar la traducción. Los ejemplos abundan, pero por motivos de actualidad nos vamos a detener en el caso de RT (antigua Russia Today), un servicio de información multimedia que funciona como televisión y plataforma de noticias multilingüe. Financiada por el Estado ruso y ligada al Kremlin, emite información en alemán, árabe, español, francés, inglés y ruso para facilitar la difusión de lo que Margarita Simonián, directora de la cadena, denomina una "realidad alternativa" (Alandete 2017).

La información es un producto estratégico, global, controlado en todas sus manifestaciones -con fines comerciales, pero también ideológicos- no solo por la industria de la comunicación, sino también por otros entes. En este contexto, la traducción es una pieza clave en la difusión mundial de los discursos mediáticos y, en especial, en el surgimiento de una opinión pública global. Las políticas traductoras que aplican los medios están al servicio de objetivos ideológicos, como ha quedado patente en diferentes estudios (Hernández Guerrero 2012 y 2016; Martín Ruano y Vidal Claramonte 2016). El fenómeno de la desinformación no ha hecho más que poner de manifiesto la necesidad de traducir, con casos como el de la plataforma rusa RT, que emite en seis idiomas; la Televisión Central China (CCTV), con ediciones en inglés, español, francés, árabe y ruso; la agencia de noticias rusa Sputnik, que opera en 33 idiomas; los canales iraníes PressTV en inglés e HispanTV en español; el canal venezolano Telesur, seguido en Latinoamérica, que recientemente lanzó la señal en inglés para el público de Estados Unidos...

El servicio de información web de RT en otros idiomas es una buena muestra de la utilización de la traducción para propagar información a una audiencia digital transnacional. Cada redacción se organiza y presenta sus contenidos de manera autónoma. El denominador común de todas ellas es una parte reducida de producción propia a la que se añade las noticias traducidas y editadas procedentes del canal matriz o de cualquiera de sus portales en otras lenguas. La fórmula es bastante simple y efectiva, ya que las noticias de esta web son muy breves, no están firmadas y basan su impacto en la información contenida en el titular. Luego, gracias a la capacidad viralizadora de plataformas como YouTube, Facebook y Twitter, su distribución a través de las redes permite que lleguen a una mayor audiencia. 


\section{Conclusiones}

Con una industria de la comunicación que controla el flujo informativo internacional con fines comerciales, pero también ideológicos, la información se ha convertido en un producto global. En el engranaje de la producción periodística, la traducción es el pilar básico que permite ampliar su difusión e impacto. Es el mecanismo de mediación, la condición sine qua non, que permite el discurrir incesante del flujo informativo global y, sin embargo, sigue siendo escasa la reflexión en torno a su importancia y, en especial, a su papel específico en las nuevas formas de comunicación del siglo XXI.

En este trabajo hemos llevado a cabo una primera aproximación al papel de la traducción en la producción de información en las nuevas formas de periodismo de la era digital. Para ello, hemos incidido en el hecho de que la actividad traductora está integrada en las labores de producción de los medios: traducir para producir contenidos es una tarea habitual en las redacciones y forma parte de la labor periodística. La necesidad de los grupos de comunicación de crecer y llegar a nuevas audiencias no ha hecho más que intensificar su uso.

Las empresas periodísticas en soporte electrónico que buscan su crecimiento y el aumento de su área de influencia crean ediciones digitales en otras lenguas que les permiten rentabilizar la información que producen mediante su traducción, o bien se sirven de modelos mixtos donde la traducción se combina con alianzas mediáticas entre grupos de comunicación afines: las fórmulas de asociación y de producción en el entorno digital son numerosas. En el caso de los medios alternativos, la traducción siempre ha sido el pilar básico sobre el que se han asentado, puesto que permite que su información trascienda del ámbito local y les proporciona visibilidad.

Los avances tecnológicos han traído parejos nuevos hábitos en el consumo de los medios de comunicación. La navegación a través de dispositivos móviles está creciendo exponencialmente y pronto superará a la conexión a internet desde ordenadores. Las empresas informativas buscan captar a este nuevo usuario que se informa a través de teléfonos inteligentes o tabletas ofreciéndole información al instante a través de sus propias aplicaciones. Las ediciones en otras lenguas basadas total o parcialmente en la traducción de contenidos propios permiten a estas plataformas rentabilizar su producción de información y ampliar mercados. Las nuevas formas de periodismo que se están afianzando en 
el entorno digital -incluidas las redes sociales y su uso como suministradoras y distribuidoras de información- han reforzado esta tendencia.

Este panorama que hemos esbozado aquí requiere de estudios más exhaustivos. Mencionábamos en el apartado anterior cómo la traducción está actuando en la configuración de los discursos que difunden los medios y en el surgimiento de una opinión pública global. Son necesarios más análisis de esta realidad, e igualmente examinar las políticas de traducción que se aplican y las relaciones de poder en la transmisión de mensajes periodísticos. Pero, además, la actividad traductora que se lleva a cabo en las nuevas formas de periodismo precisa de estudios que analicen cómo se integra esta práctica en la labor de los profesionales, qué perfiles requiere y cuáles son las competencias necesarias. Estos trabajos resultarán beneficiosos tanto para los Estudios de Traducción como para los de Comunicación.

\section{Referencias bibliográficas}

Alandete, David. (2017) "RT, Sputnik y la nueva guerra rusa." El País, 31 de diciembre de 2017. Versión electrónica: <https://politica.elpais.com/politica/2017/12/31/actualidad/1514736685_318060.html>

Allan, Stuart \& Einar Thorsen (eds.) (2009) Citizen Journalism: Global Perspectives. New York: Peter Lang.

BAKER, Mona. (2012) "Translation as an Alternative Space for Political Action." Social Movement Studies 12:1, pp. 23-47.

BAUMANN, Gerd; Marie Gillespie \& Annabelle Sreberny. (2011a) "Transcultural journalism and the politics of translation: Interrogating the BBC World Service." Journalism 12:2, pp. 135-142.

BAUMANN, Gerd; Marie Gillespie \& Annabelle Sreberny. (2011b) "Transcultural journalism: Translations, transmissions and transformations." Journalism 12:2, pp. 235-238.

BIELSA, Esperança \& Susan Bassnett. (2009) Translation in global news. London: Routledge.

CASERO-RIPOlLÉS, Andreu. (2015) "Nuevos proveedores de información periodística en el entorno digital: los infomediarios de segunda generación." Anuario ThinkEPI 9, pp. 172-176.

CORTÉs ZABORRAS, Carmen \& María José Hernández Guerrero (eds.) (2005) La traducción periodística. Cuenca: Ediciones de la Universidad de Castilla La Mancha. 
DAVIER, Lucille. (2017) Les enjeux de la traduction dans les agences de presse. Lille: Presses Universitaires du Septentrion.

FRY, Deborah. (2003) Guía de introducción al sector de la localización (2 ${ }^{\mathrm{a}}$ edición revisada por Arle Lommel y traducida por Hermes Traducciones y Servicios Lingüísticos, S.L.). Suecia: LISA [Localisation Industry Standards Association].

GALLARDO CAMACHO, Jorge. (2005) "El redactor-traductor en los grandes medios de comunicación con mercados multilingües: caso CNN." Zer. Revista de Estudios de Comunicación 19, pp. 77-87.

GARCÍA AlARCÓN, Victoria. (2017) "La figura del traductor en los nuevos medios de comunicación." En: Ortega Arjonilla, Emilio et al. (eds.) Cartografía de la traducción, la interpretación y las industrias de la lengua. Granada: Comares, pp. 95-112.

GiLlmor, Dan. (2004) We the Media: Grassroots Journalism by the People, for the People. Sebastopol: CA: O'Reilly Media.

GILLMOR, Dan. (2010) Mediactive. Versión electrónica: <http://www.mediactive. com>

Hernández Guerrero, María José. (2009) Traducción y periodismo. Bern: Peter Lang.

HernÁNDEZ Guerrero, María José. (2012) "La traducción al servicio de una línea editorial: la primavera árabe en el diario El País.” Meta 57:4, pp. 960-976.

Hernández Guerrero, María José. (2015) "La traducción en The Huffington Post." Hermeneus 17, pp. 111-136.

HERNÁNDEZ GuERRERO, María José. (2016). "Traducción y opinión pública global: el caso de Project Syndicate." En: Martín Ruano, María Rosario \& África Vidal Claramonte (eds.) 2016. Traducción, medios de comunicación, opinión pública. Granada: Comares, pp. 53-72.

HernÁndez Guerrero, María José. (2017) "Translation in New Independent Online Media: The Case of Mediapart." Perspectives 25:2, pp. 294-307.

Hernando, Bernardino M. (1999) "Traducción y periodismo o el doble y misterioso escepticismo." Estudios sobre el mensaje periodístico 5, pp. 129-141.

JuRIS, Jeffrey S. (2004) "Indymedia: de la contra información a la utopía informacional.” En: Marí Sáez, Víctor M. (ed.) 2004. La red es de todos: cuando los movimientos sociales se apropian de la red. Madrid: Editorial Popular, pp. 154-177. 
KwaK, Haewoon; Changhyun Lee; Hosung Park \& Sue Moon. (2010) "What is Twitter a Social Network or a News Media?” Proc WWW'10, pp. 591-600. Versión electrónica: <http://www.ambuehler.ethz.ch/CDstore/www2010/ www/p591.pdf>

López García, Xosé. (2010) La metamorfosis del periodismo. Historia de lo que permanece y de lo que cambia en ciberperiodismo del tercer milenio. Sevilla \& Zamora: Comunicación Social.

LULE, Jack. (2012) Globalization and Media: Global Village of Babel. Lantham MD: Rowman \& Littlefield Publishers, Inc.

MARTín RuANO, María Rosario \& África Vidal Claramonte (eds.) (2016) Traducción, medios de comunicación, opinión pública. Granada: Comares.

OrENGO, Alberto. (2005) "Localising News: Translation and the 'Global-national' Dichotomy." Language and Intercultural Comunication 5:2, pp. 168-187.

PALMER, Jerry. (2009) "News gathering and dissemination." En: Baker, Mona \& Gabriela Saldanha (eds.) 2009. Routledge Encyclopedia of Translation Studies (2nd ed.). London: Routledge, pp. 186-189.

PAUla BATISTA, Renilse. (2016) Traducción y periodismo: La identidad brasileña en la prensa digital española El País. Tesis doctoral. Salamanca: Universidad de Salamanca. Versión electrónica: <https://gredos.usal.es/jspui/ handle/10366/128499>

PÉREZ-GonZÁlez, Luis. (2010) "Ad-hocracies of Translation Activism in the Blogosphere. A Genealogical Case Study.” En: Baker, Mona et al. (eds.) 2010. Text and Context. Manchester: St Jerome Publishing, pp. 259-287.

Plaza ÉCIJA, Sara. (2013) "Twitter convierte en "noticia" información que los medios tradicionales no cubren." Periodismo ciudadano. Versión electrónica: $<$ http://www.periodismociudadano.com/2013/07/19/twitter-convierte-en-noticia-informacion-que-los-medios-tradicionales-no-cubren/>

PYM, Anthony. (2004) The Moving Text. Localization, translation, and distribution. Amsterdam \& Philadelphia: John Benjamins.

Rosenberry, Jack \& Burton St John (eds.) (2010) Public Journalism 2.0: The Promise and Reality of a Citizen Engaged Press. New York: Routledge.

Salaverría, Ramón (ed.) (2005) Cibermedios. El impacto de internet en los medios de comunicación en España. Sevilla: Comunicación Social Ediciones y Publicaciones.

SAlzBERG, Chris. (2008) "Translation and Participatory Media: Experiences from Global Voices." Translation Journal 12:3. Versión electrónica: <http://translationjournal.net/journal/45global.htm> 
SCAmmell, Claire. (2018) Translation Strategies in Global News. Cham: Palgrave Pivot.

SOLER, Jordi. (2017) "El espectáculo vale más que la verdad." El País, 27 de mayo de 2017. Versión electrónica: <https://elpais.com/elpais/2017/05/27/ opinion/1495899022_667227.html>

Stetting, Karen. (1989) "Transediting. A New Term for Coping with the Grey Area between Editing and Translating." En: Caie, Graham et al. (eds.) 1989. Proceedings from the Fourth Nordic Conference for English Studies. Copenhagen: University of Copenhagen, pp. 371-382.

TALENS, Manuel. (2010a) "Traducción y compromiso." En: González, Luis \& Pollux Hernúñez (eds.) 2010. El español, lengua de traducción para la cooperación y el diálogo. Madrid: ESLETRA, pp. 119-128. Versión electrónica: <http://cvc.cervantes.es/lengua/esletra/pdf/04/016_talens.pdf >

TALENS, Manuel. (2010b) "Las lenguas de Tlaxcala: Pequeña historia de una larga marcha." En: Boéri, Julie \& Carol Maier (eds.) 2010. Compromiso social y Traducción/Interpretación. Granada: ECOS, Traductores e Intérpretes por la Solidaridad, pp. 179-184.

Torregrosa, Carlos. (2017) “¿Quiénes somos? ¡Conoce a BeSoccer!” BeSoccer. com, 10 de mayo de 2017. Versión electrónica: <https://es.besoccer.com/ noticia/quienes-somos-conoce-a-besoccer>

VALDEÓN, Roberto A. (ed.) (2010) Translating information. Oviedo: Ediuno.

VAlDEÓn, Roberto A. (ed.) (2012) Translation and journalism. Special issue of Meta 57:4.

VALDEÓN, Roberto A. (2015) "Fifteen years of journalistic translation research and more." Perspectives: Studies in Translatology 23:4, pp. 634-662.

VALDEÓn, Roberto A. (2016) "Traducción periodística y gatekeeping." En Martín Ruano, María Rosario \& África Vidal Claramonte (eds.) 2016. Traducción, medios de comunicación, opinión pública. Granada: Comares, pp. 35-51.

VALDEÓN, Roberto A. (2018) "On the use of the term 'translation' in journalism studies.” Journalism 19:2, pp. 252-269.

VERSCHUEREN, Jeff. (2007) "The Interventionist Role of (Re)contextualization in Translation." En: Munday, Jeremy (ed.) 2007. Translation as Intervention. London \& New York: Continuum, pp. 71-83.

VUORINEN, Erkka. (1995) "News Translation as Gatekeeping." En: Snell-Hornby, Mary et al. (eds.). Translation as Intercultural Communication. Amsterdam \& Philadelphia: John Benjamins, pp.161-172. 
WILKE, Jürgen \& Bernhard Rosenberger. (1994) "Importing foreign news: A case study of the German Service of the Associated Press." Journalism \& Mass Communication Quarterly 71: 2, pp. 421-432.

ZuCKerman, Ethan. (2013) Rewire: Digital Cosmopolitans in the Age of Connection. New York: W.W. Norton \& Company Ltd.

\section{NOTA BIOGRÁFICA / BIONOTE}

MARÍA José HeRnández GuerRero es profesora titular del Departamento de Traducción e Interpretación de la Universidad de Málaga y miembro del Grupo de Investigación Traductología e Interculturalidad (HUM 412). Entre sus principales líneas de investigación se encuentra la traducción periodística. Ha sido directora de Trans. Revista de Traductología y coordinadora del Máster Oficial en Traducción para el Mundo Editorial de la Universidad de Málaga, en el que imparte la asignatura de Traducción Editorial: Textos Periodísticos. Es autora de numerosas publicaciones sobre este tema en las principales revistas del área (como Meta: Translators' Journal, Across Languages and Cultures, Perspectives, Hermeneus, etc.) y de los siguientes libros: La traducción periodística (Universidad de Castilla La Mancha, 2005, editado junto con Carmen Cortés) y Traducción y periodismo (Peter Lang, 2009), entre otros trabajos.

MARÍA JosÉ HERNÁNDEZ GUERRERO is tenured lecturer in the Department of Translation and Interpreting at the Universidad de Málaga, Spain, and a member of the Grupo de Investigación Traductología e Interculturalidad (HUM 412). News translation and journalistic translation are some of her main lines of investigation. She has worked as editor of TRANS. Revista de Traductología and as director of the MA in Translation for the Publishing Industry. She teaches the Journalistic Translation subject on this Masters. She has published widely in the major journals in this area, such as Meta: Translators' Journal, Across Languages and Cultures, Perspectives, Hermeneus, etc. She is co-editor of La traducción periodística [Journalistic Translation] (Universidad de Castilla La Mancha, 2005) and the author of Traducción y periodismo [Translation and Journalism] (Peter Lang 2009), among many other works. 